\title{
Calculation Approaches for Determining the Sliding Friction Coefficient - Analytical Consideration and FE-Modelling
}

\author{
André Bergmann ${ }^{1 *}$, Niels Dallinger ${ }^{1}$, Timo Bensing ${ }^{2}$, Yvonne Keil ${ }^{2}$, \\ Markus Golder ${ }^{1}$, Martin Moneke ${ }^{2}$ \\ 1 Professorship of Conveying Engineering and Materials Handling, Chemnitz University of Technology, Germany \\ 2 Institute of Plastics Engineering, Darmstadt University of Applied Sciences, Germany \\ * Correspondence: andre.bergmann@mb.tu-chemnitz.de
}

Received 21 October 2020; Accepted 22 October 2020; Available online 7 December 2020

(C) 2020 by A. Bergmann et al. This is an open access article distributed under the Creative Commons Attribution License (CC-BY 4.0), which permits unrestricted use, distribution, and reproduction in any medium, provided the original work is properly cited.

\begin{abstract}
Microstructures on polymer surfaces are known to reduce friction and the visibility of scratches. Due to the complex interaction of multiple surface areas in contact with each other the prediction of coefficient of friction (COF) or wear is difficult and depends on an empirical solution. This article deals with possibilities of calculating the deforming part of friction via an analytical solution and a FE-model. In a first step the modelling of single contacts is demonstrated. The analytical calculation based on the Hertzian contact equations is extended regarding viscoelastic material parameters. The basic approach of FE-modelling is explained including calibration of the material model using the software MCalibration ${ }^{\circledR}$. The article introduces the different procedures of simulating and modelling COF and wear taking into account the area of contact and resulting stress distribution.
\end{abstract}

KEYWORDS friction, wear, scratch test, simulation

\section{Introduction}

Engineering thermoplastics such as ultra-high-molecular-weight polyethylen (PE-UHMW), polyoxymethylene (POM) or polypropylene (PP) are commonly used in all areas of industry including automotive, materials handling or medical engineering. Besides the advantage of possible low-cost production by injection moulding or extrusion polymers have selflubrication properties which enable the tribological use under dry conditions.

Previously various investigations were made to improve the tribological behaviour by adding additives like polytetrafluoroethylene (PTFE) or silicone oil [1]. Typical disadvantages by using additives are on one hand the reduction of mechanical properties and on the other hand the necessity to modify the moulding parameters and/or tools. Another way to improve COF and wear is the micro-structuring of the contacting 


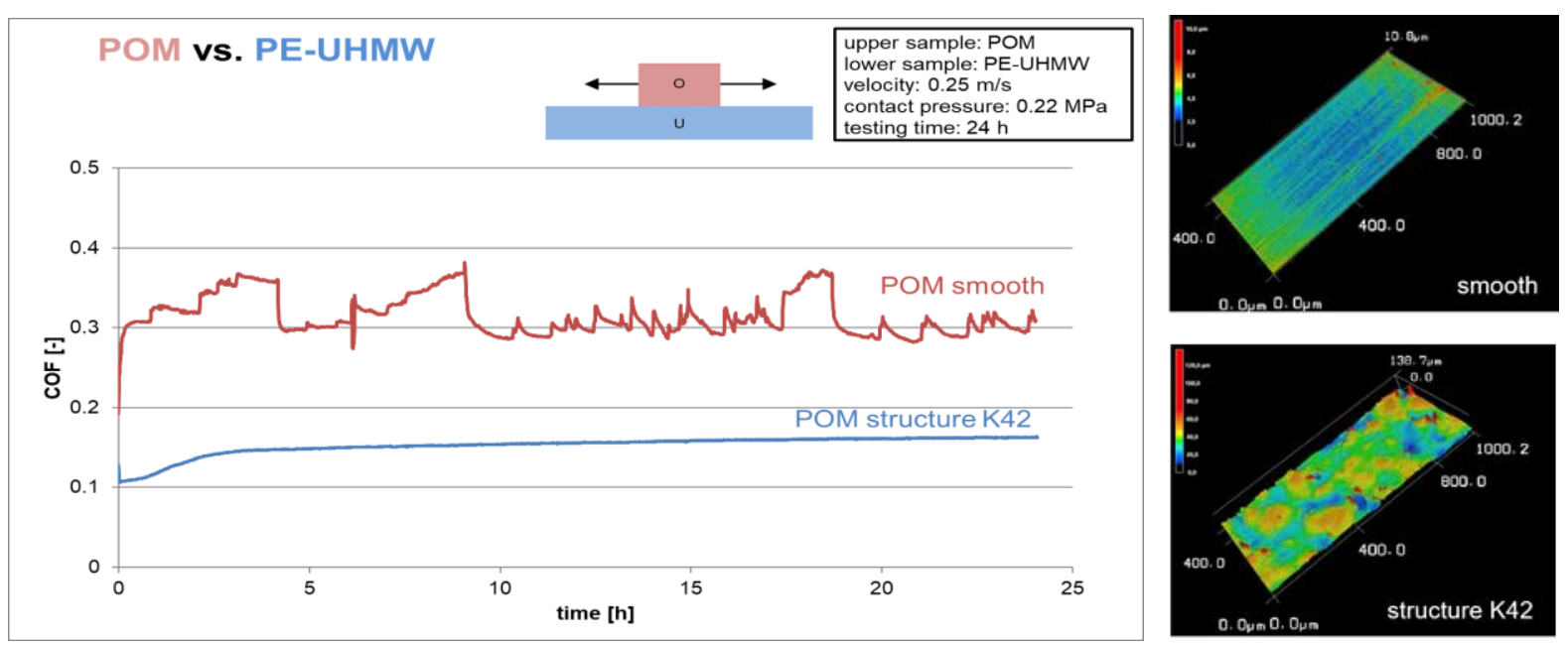

Figure 1: left) COF over time, measured on an oscillating test bench; right) image of smooth and structured surface of POM sample

surfaces [1,2]. As an example, Figure 1 shows the COF over $24 \mathrm{~h}$ of testing of two different surfaces on POM samples. COF of the smooth sample is almost doubled in comparison to the structured one which has an eroded structure class K42 (see [3]). Other researchers report similar results $[4,5,6,7,8,9]$.

Structured surfaces also have an impact on the scratch resistance and therefore the visibility of scratches. As an example, using truncated pyramids on the surface of acrylonitrile butadiene styrene (ABS) results in a lower penetration depth in comparison to smooth surfaces (see Figure 2) while the tangential forces in and across the scratch direction increases [10]. Furthermore, varying the pattern of the structured surface like increasing surface roughness or lowering the distance between periodic bumps can improve scratch visibility $[11,12]$.

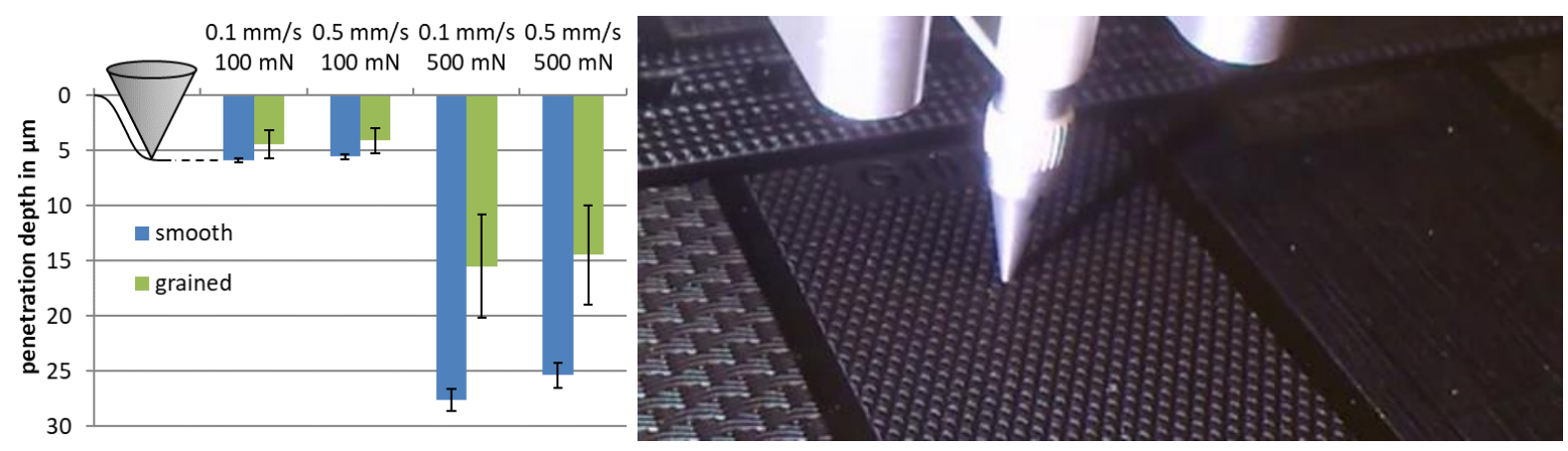

Figure 2: left) Penetration depth of smooth and grained surface under different loads and velocities, measured on a scratch test machine (Innowep UST 1000); right) Grained surface positioned under the scratch tip [10]

Due to the complex interaction while sliding with multiple contacts it is not possible to estimate the true area of contact or furthermore the pressure distribution on the surface. As shown in Figure 3 the worn surface of the sample has various contact areas which probably increase during the long-time test. All the investigations mentioned are more or less empirical by varying the density, shape or distribution of surface structures.

The aim of this research project is to separate these multiple contacts into single contacts as a first step. The investigation of the single contact regarding the true area of contact and 
pressure distribution is a requirement of calculating multiple contacts. Therefor an analytical model and a FE-model are developed.
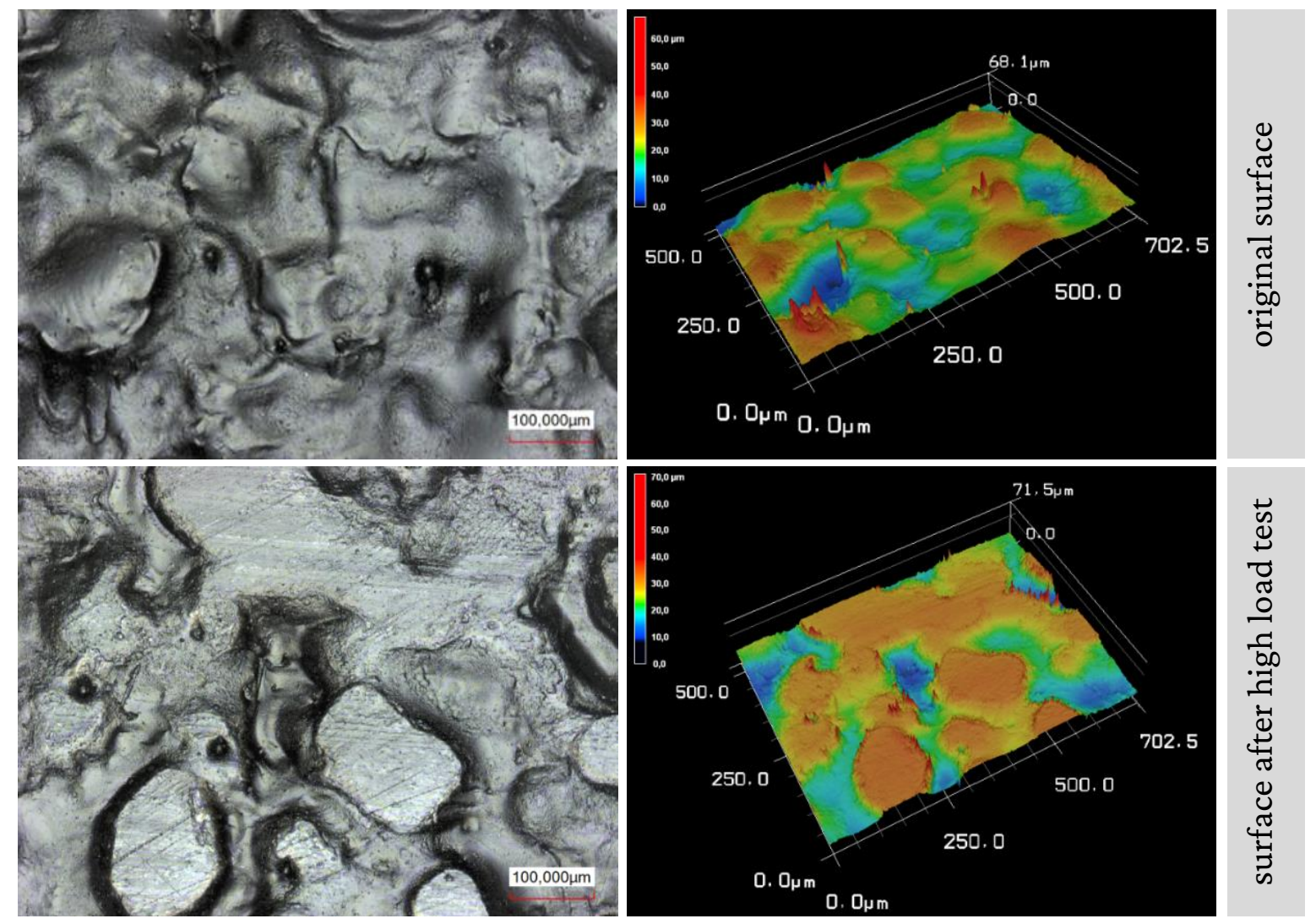

Figure 3: top) original surface of a POM sample with eroded surface (K36); bottom) worn surface of the same sample after $24 \mathrm{~h}$ friction test with high load $\left(\mathrm{F}_{\mathrm{N}}=75 \mathrm{~N}\right)$

\section{Experimental Setup}

For the investigation of friction and wear (or deformation), basically two testing machines are utilized:

- small scale, scratch test machine UST 1000 from Innowep and

- large scale, pin/ball on disc test machine (self-made at TU Chemnitz).

These two test benches together allow for a large variation of testing parameters (e.g. normal force, velocity, indenter shape). While the scratch test machine (see Figure 4) measures the penetration depth during a single stroke with applied normal loads up to $1 \mathrm{~N}$ and a velocities up to $2,5 \mathrm{~mm} / \mathrm{s}$, the pin/ball on disc test machine (see Figure 5) is able to measure friction and deformation over long time (up to $400 \mathrm{~h}$ ). Furthermore, the normal force can be set up to $300 \mathrm{~N}$ and the velocity is limited to $1500 \mathrm{~mm} / \mathrm{s}$.

The combination of test benches enables the detection from the onset of sliding friction till the long-time evolution and is necessary for the development of the analytical and FE-model. 

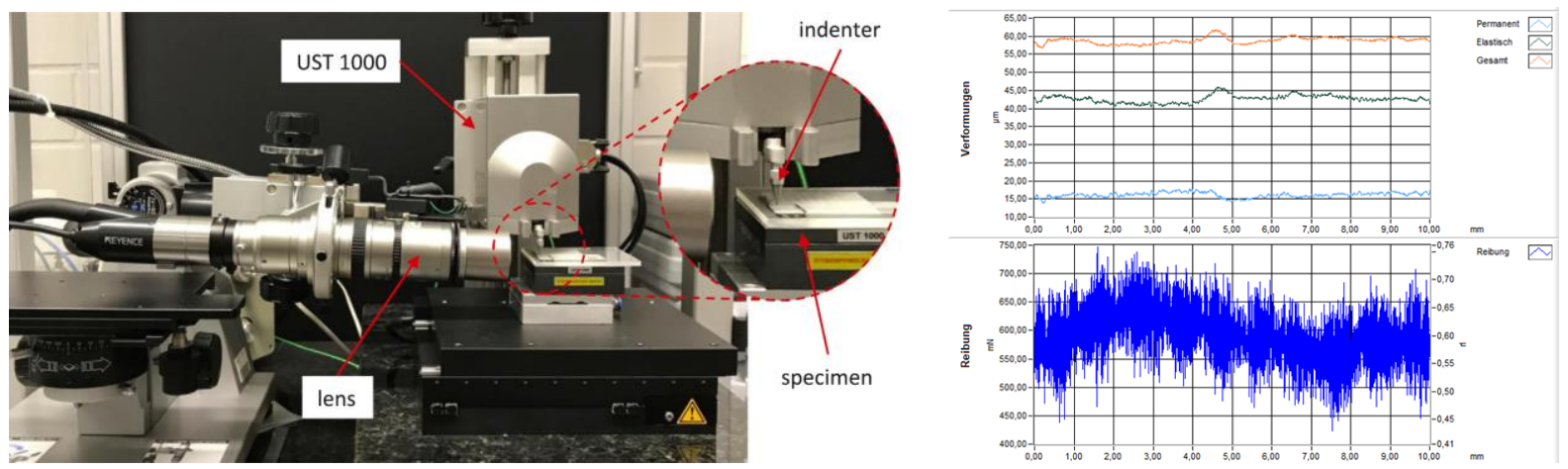

Figure 4: Scratch test machine from Innowep (Type UST 1000) [13] and measurement data of deformation and COF of PE-UHMW over $10 \mathrm{~mm}$
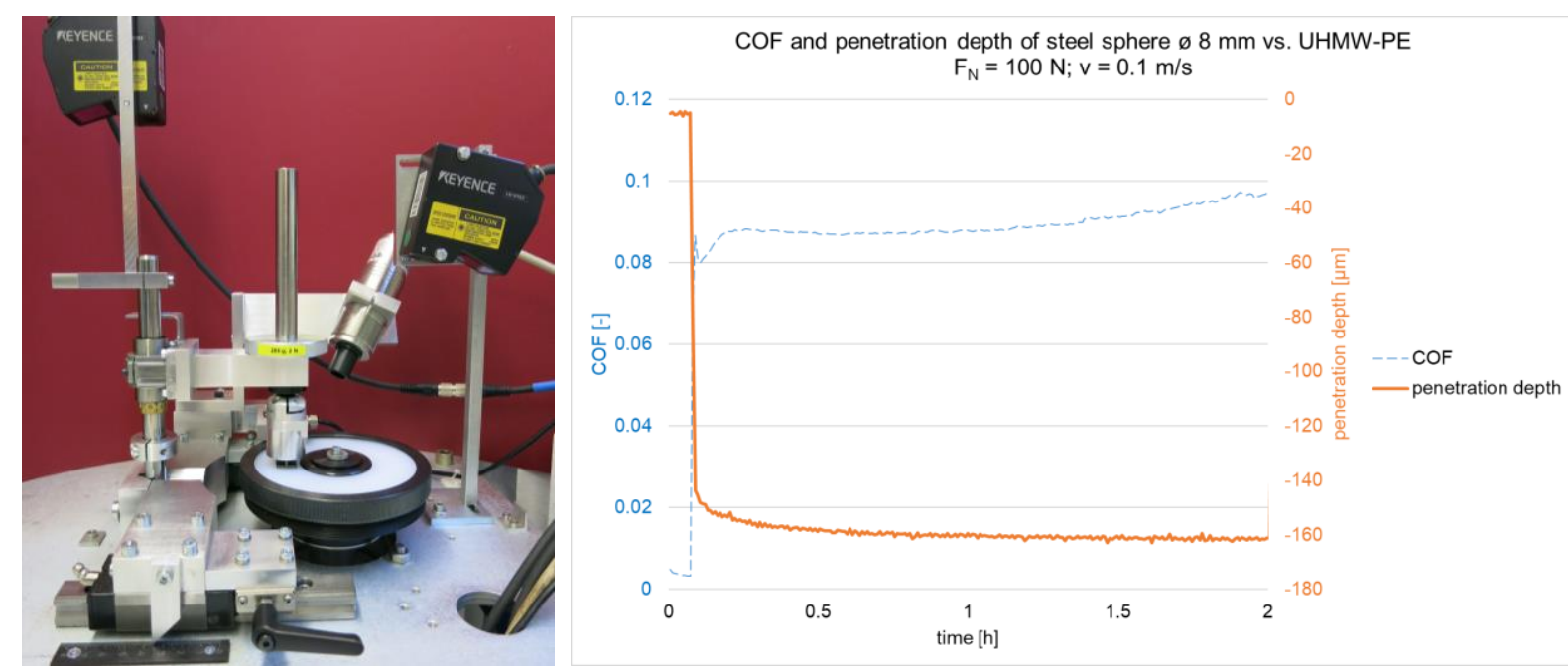

Figure 5: Pin/ball on disc test machine including temperature measurement and measurement data of deformation and COF of PE-UHMW over $2 \mathrm{~h}$

\section{Modelling}

\subsection{Analytical Model}

The analytical calculation of two bodies with single contact is based on Hertzian equations. The idea behind this approach is to calculate the contact area from which deformative and adhesive parts of friction arise.

As an example of the procedure, Figure 6 shows the running track and a steel sphere after a friction test of $24 \mathrm{~h}$, made with an oscillating friction test machine (further explanation [14]). Half the width of the running track equals one of the two radii (see Figure 7). The other radius is infinite. For the rigid sphere both radii equal $8 \mathrm{~mm}$.

The test benches allow the detection of the penetration depth which in turn enables the precise calculation of the contact radius considering the adapted equations of [15], see Figure 7. 
Assuming a static contact at the moment of calculation, contact radii $a$ and $b$ of the forming ellipse can be calculated (see Figure 8 left). On the right side of Figure 8 the intersection $A$ is shown which includes the radius of the running track $r_{\text {track. }}$
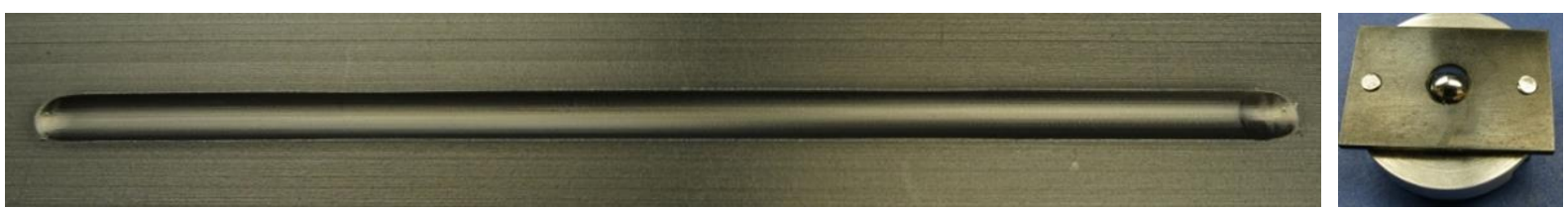

Figure 6: left) running track in a sample of PE-UHMW (oscillating test) and right) steel sphere $\varnothing 8 \mathrm{~mm}$ in sample holder
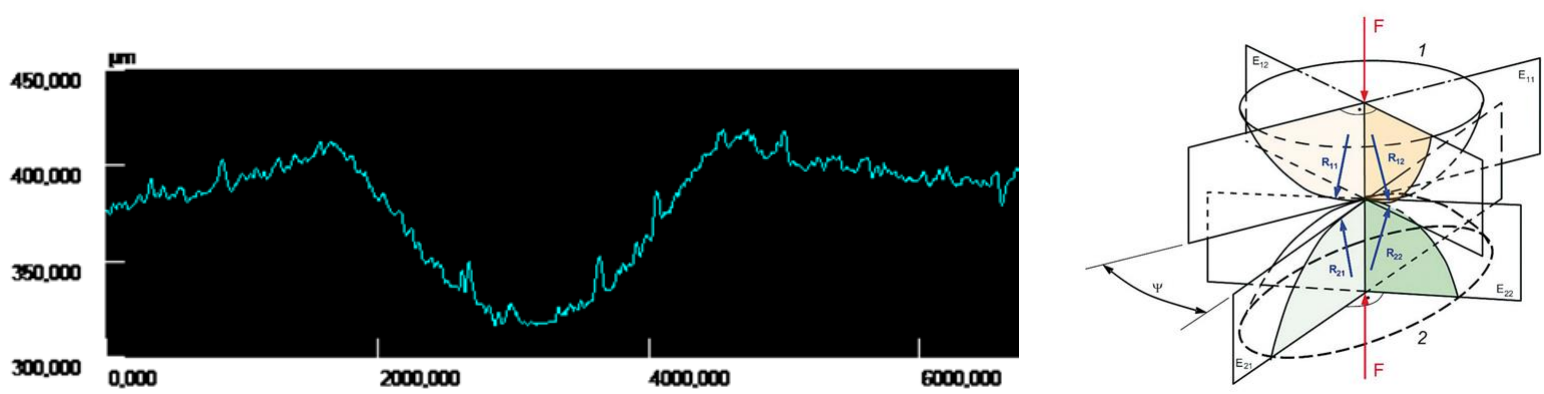

Figure 7: left) profile of running track on PE-UHMW and right) contact conditions of bodies curved on all sites [15]

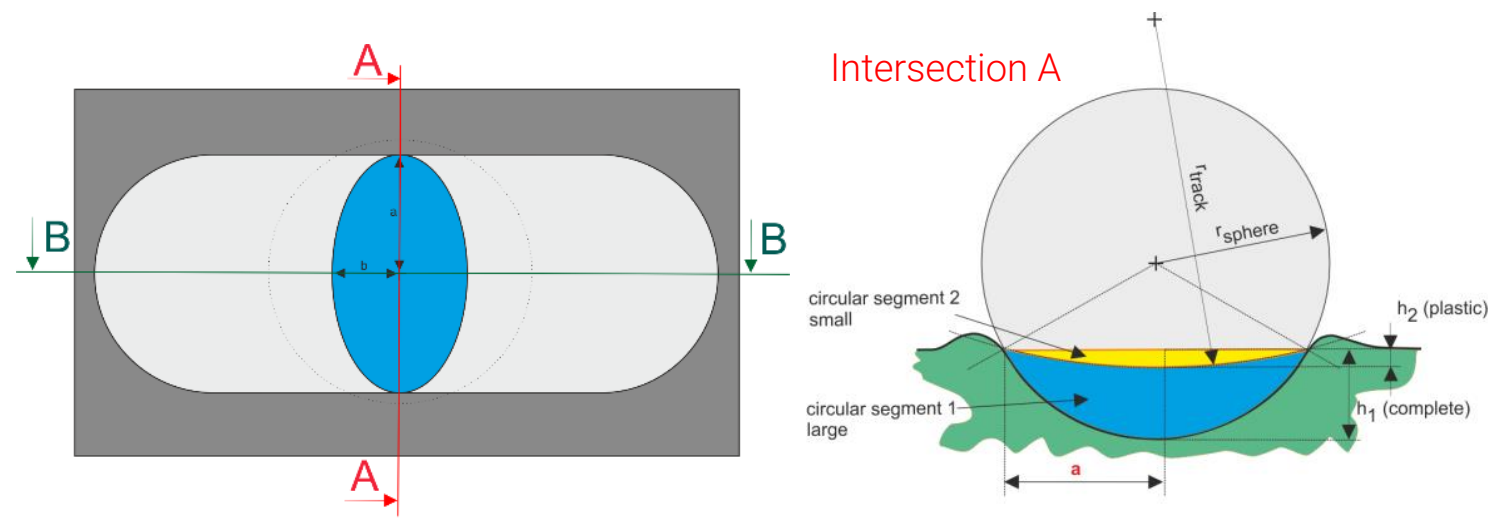

Figure 8: left) profile of static Hertzian contact and right) intersection A with corresponding radius a
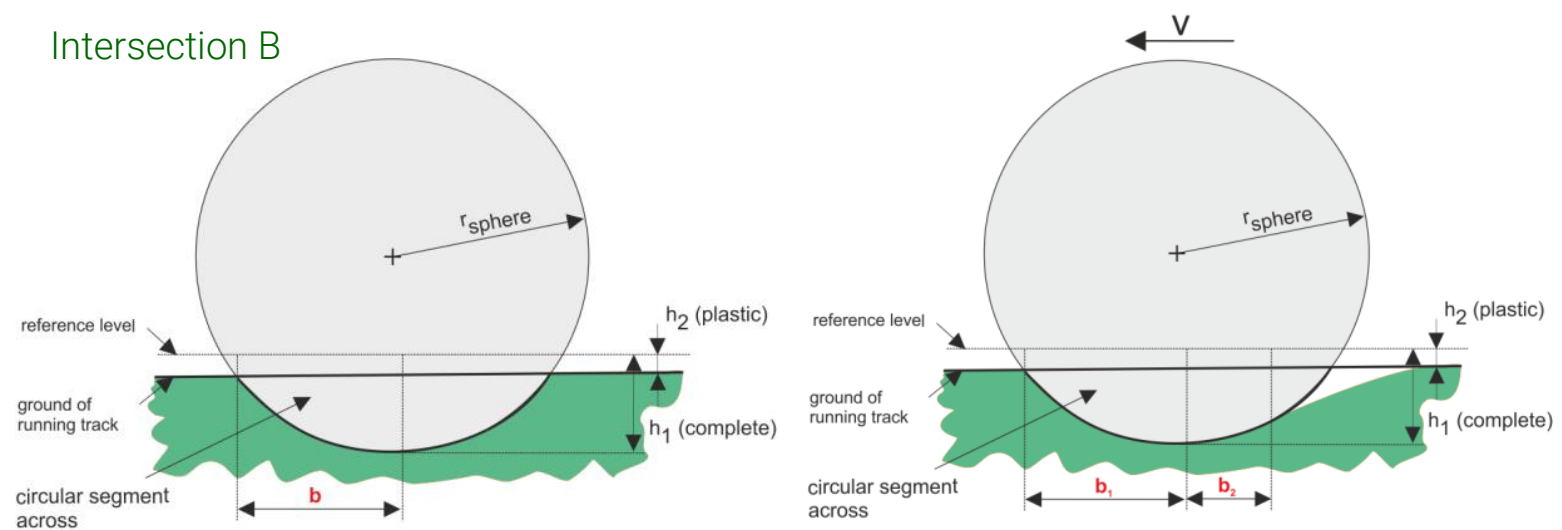

Figure 9: Intersection $\mathrm{B}$ with left) static case with constant radius $b$ and right) with motion and resulting radii $b_{1}$ and $b_{2}$ 
In Figure 9 intersection B is shown. On the left side the static case is represented by a single radius $b$. On the right side, which includes sliding motion of the sphere, radius $b$ is split into two separate contact radii. $b_{1}$ is in front of the sphere, meaning in direction of motion and is similar to the static radius $b . b_{2}$ is formed behind the sphere and can vary between $O$ and $b_{1}$. These two cases can be interpreted as:

$-b_{2}=O$ fully plastic deformation and

- $b_{2}=b_{1}$ fully elastic deformation

These results have to be considered as the background for calculating the deformative part of friction $\mu_{d e f}$. In $[16,17]$ the author extended the solution of [18] which was only able to handle fully plastic deformation. Lafaye $[16,17]$ introduced a rear angle $\omega$, depending on the elastic recovery behind the indenter. In Figure 10 the resulting contact areas $S_{n}$ and $S_{t}$ are shown. The ratio of these two areas form $\mu_{\text {def }}$ (eq. (1)).

$$
\mu_{\text {def }}=\frac{S_{t}}{S_{n}}
$$

Considering the rear angle $\omega$ equation (2) can be found:

$$
\mu_{\text {def }}=\frac{2}{a^{2}} * \frac{\rho^{2} \sin ^{-1}\left(a \cos \frac{\omega}{\rho}\right)-a \cos \omega \sqrt{\rho^{2}-a^{2} \cos ^{2} \omega}}{\pi+2 \omega+\sin 2 \omega}
$$

Where $\rho$ is the radius of the truncated disc $S_{t}$ following equation (3)

$$
\rho=R^{2}-a^{2} \sin ^{2} \omega
$$

The only missing parameter in equation (2) is $\mu_{\text {def, }}$ which can be measured with lubricated sliding experiments as described in [19]. As an example, Figure 11 shows two experiments, one under dry sliding conditions and one lubricated with silicone oil where $\mu_{\text {lubricated }}$ equals $\mu_{\text {def. }}$

Knowing $\mu_{\text {def }}$ and the penetration depth, $\omega$ can now be calculated. Figure 12 shows the first results using equation (2). For the presented example in Figure 11 the rear angle is about $40^{\circ}$ (bright red line).

Note: The shown results are preliminary because they are based on the simplification of [16] which only takes into account the contact of sphere to plane, resulting in one contact radius a. For our case the contact equations must be extended with regard to the elliptical shape of the forming contact, including radii $a$ and $b$.

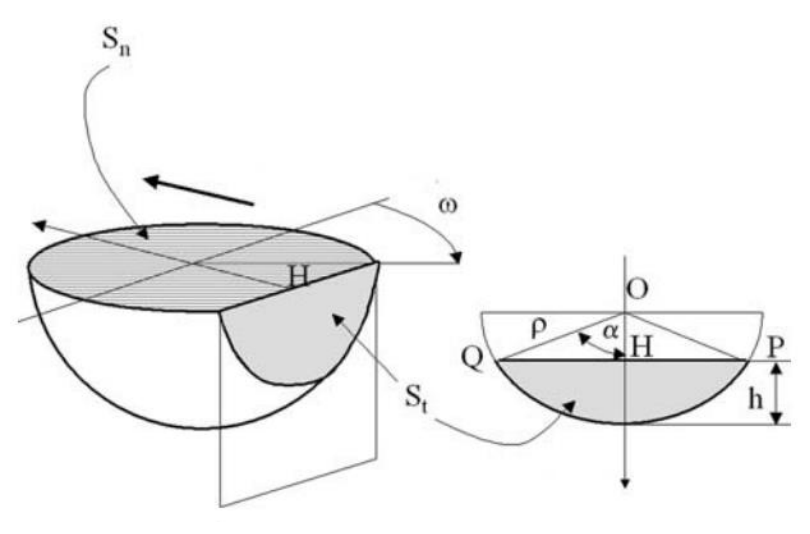

Figure 10: Definition of the resulting contact areas with $S_{n}$ normal section and $S_{t}$ cross section (without contact) according [16] 
These results show that it is possible to calculate the area of contact with respect to the rear angle $\omega$. In the further progress of the project the contact area of different radii of spheres, different loads and velocities should be calculated. The model is then extended to adhesive components in terms of the JKR-theorem which is considered best for "soft" materials like polymers $[20,21]$. The advantage of the presented experiments is that the adhesive part of friction $\mu_{a d h}$ can be determined from the difference between dry and lubricated experiments (see Figure 11).

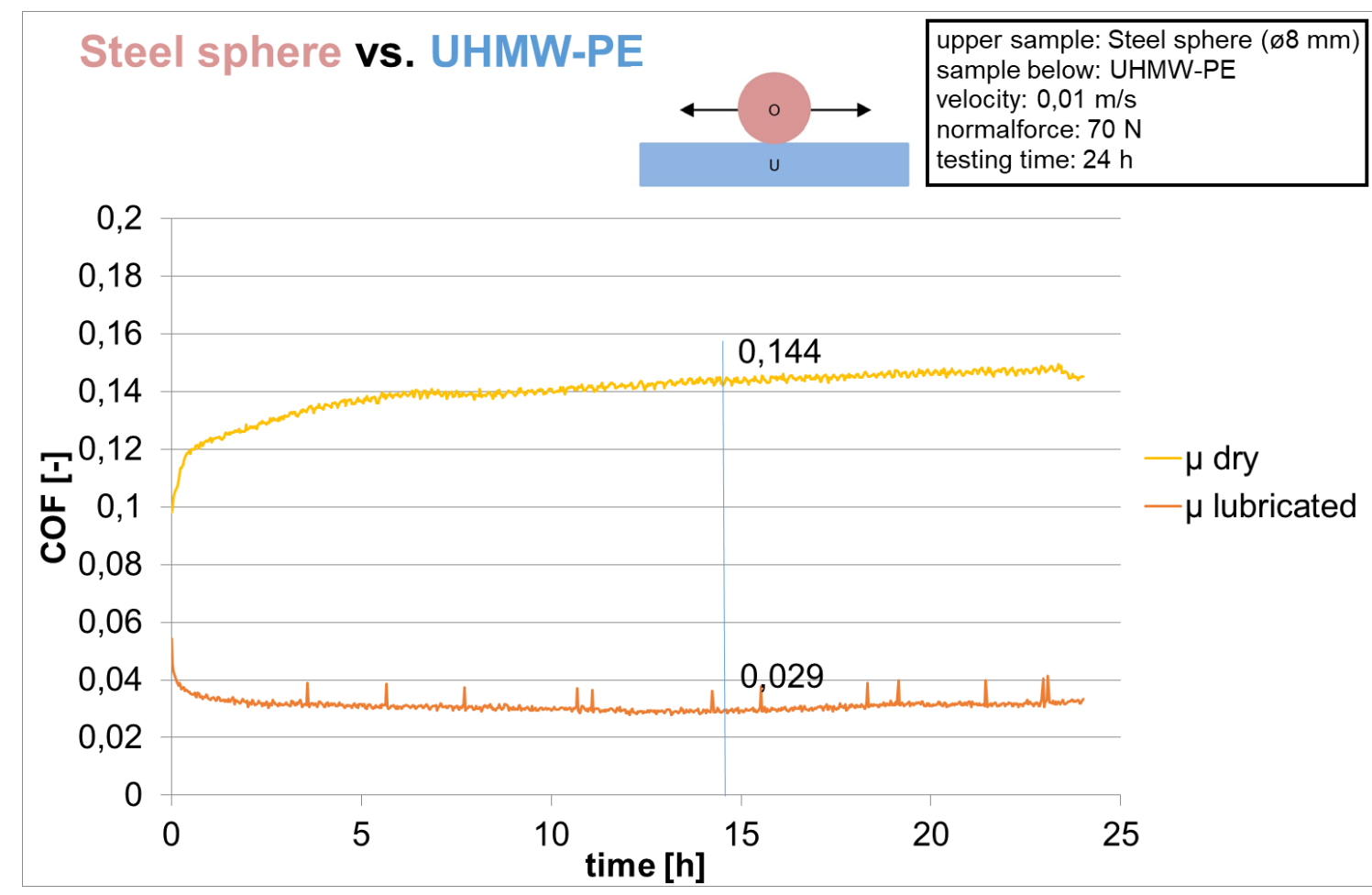

Figure 11: COF under dry and lubricated conditions over $24 \mathrm{~h}$ testing duration

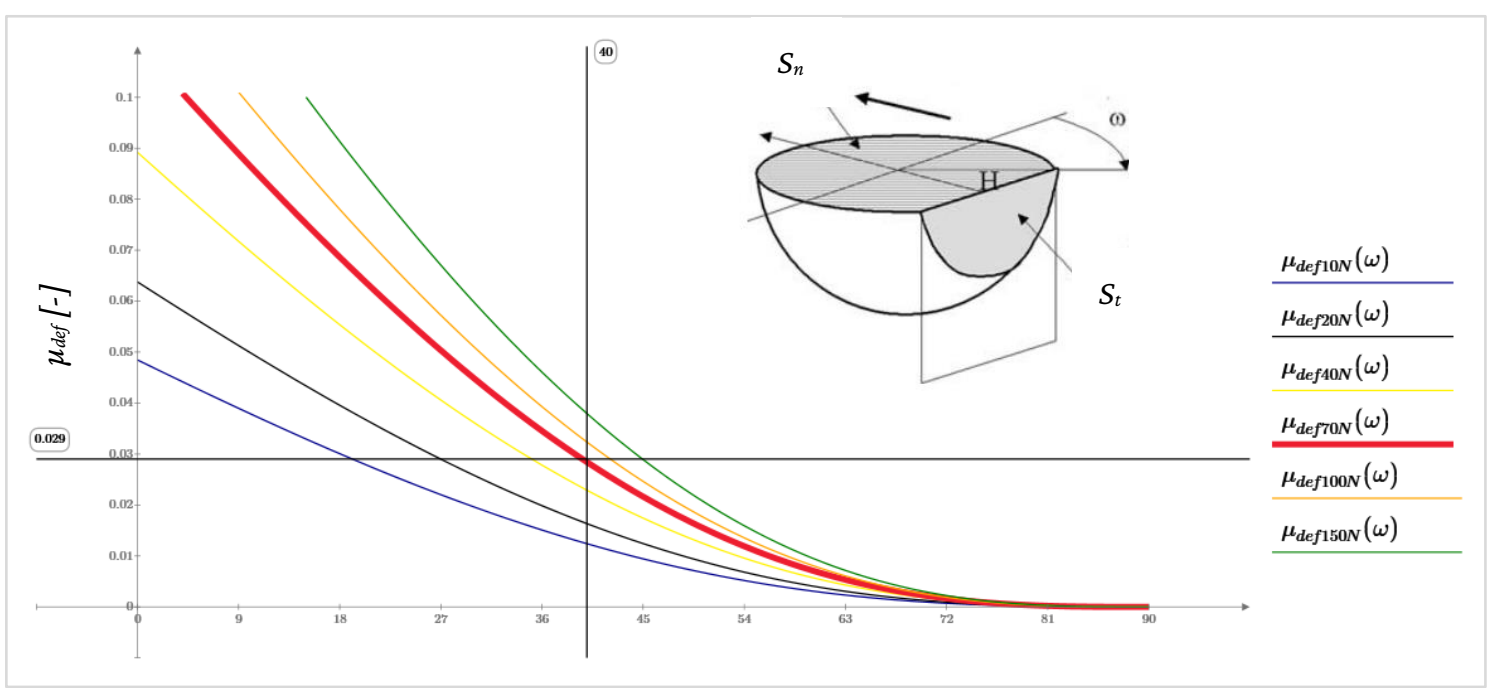

Figure 12: Calculated rear angle $\omega$ depending on $\mu_{d e f}$ for different normal forces 


\subsection{FE-Model}

The finite element modelling is done by the software Abaqus ${ }^{\circledR}$. Due to the fact that friction and scratching are both dynamic processes, the use of the dynamic explicit solver is required. Within the simulation models, ALE adaptive meshing is applied, which maintains a highquality mesh throughout an analysis. It is used as a continuous adaptive meshing tool for large deformations (plastic deformation, dynamic impact), which typically occur during scratching and long-time friction experiments.

First of all, the material models for the polymers POM, PP and PE-UHMW are created by $2 \mathrm{D}$ modelling. This enables a time-saving calibration of the complex material models in comparison to 3D models.

One drawback of the $2 \mathrm{D}$ model is, that only rotationally symmetric contacts can be modelled. For this reason, instrumented indentation tests are performed to calibrate the $2 \mathrm{D}$ model. Figure 13 shows two examples for PP and PE-UHMW at the same loading of $900 \mathrm{mN}$.

For calibrating the material models for the investigated polymers two additional software packages are used:

- MCalibration ${ }^{\mathbb{R}}$ : Software for calibrating material models for FEM software via experiments (fitting of existing models)

- PolyUMod $\AA$ : enables the integration of the material model in Abaqus ${ }^{\circledR}$ (via subroutines)

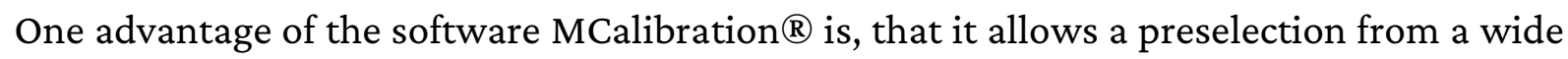
range of material models, which are then fitted to real measurement data. For polymers such as PP and PE-UHMW the Three-Network-Model (see Figure 14 left) regarding [22] allows

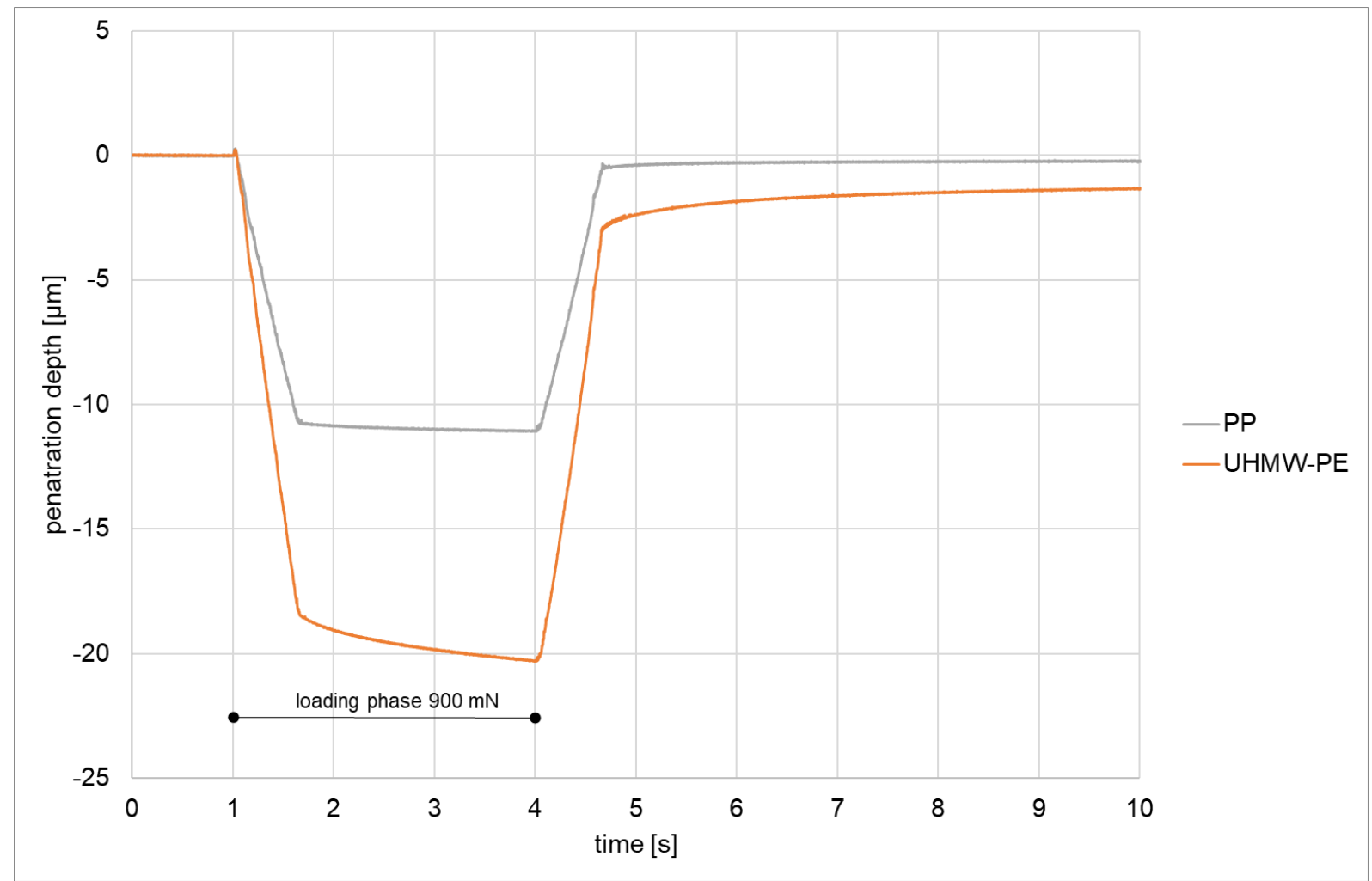

Figure 13: Instrumented indentation tests on PP and PE-UHMW with a steel indenter (sphere ø 1,8 $\mathrm{mm}$ ) 
the best fit. After the preselection of the basic model different experimental data e.g. uniaxial tension or compression tests can be loaded into the program and the model is fitted. Furthermore, virtual experiments with defined conditions can be made (Figure 14 right)

As a first experimental impression Figure 15 shows the results of an uniaxial tension test with three different strain rates for PE-UHMW. It is apparent that the higher the strain rate, the higher the stress. Further experiments regarding cyclic tension tests and compression tests are planned. They can be used to increase the accuracy of the material model.

After implementing the fitted material model into Abaqus ${ }^{\circledR}$ via PolyUMod ${ }^{\circledR}$ the 2D-simulation can be calibrated using the data of the indentation tests (e.g. Figure 13).
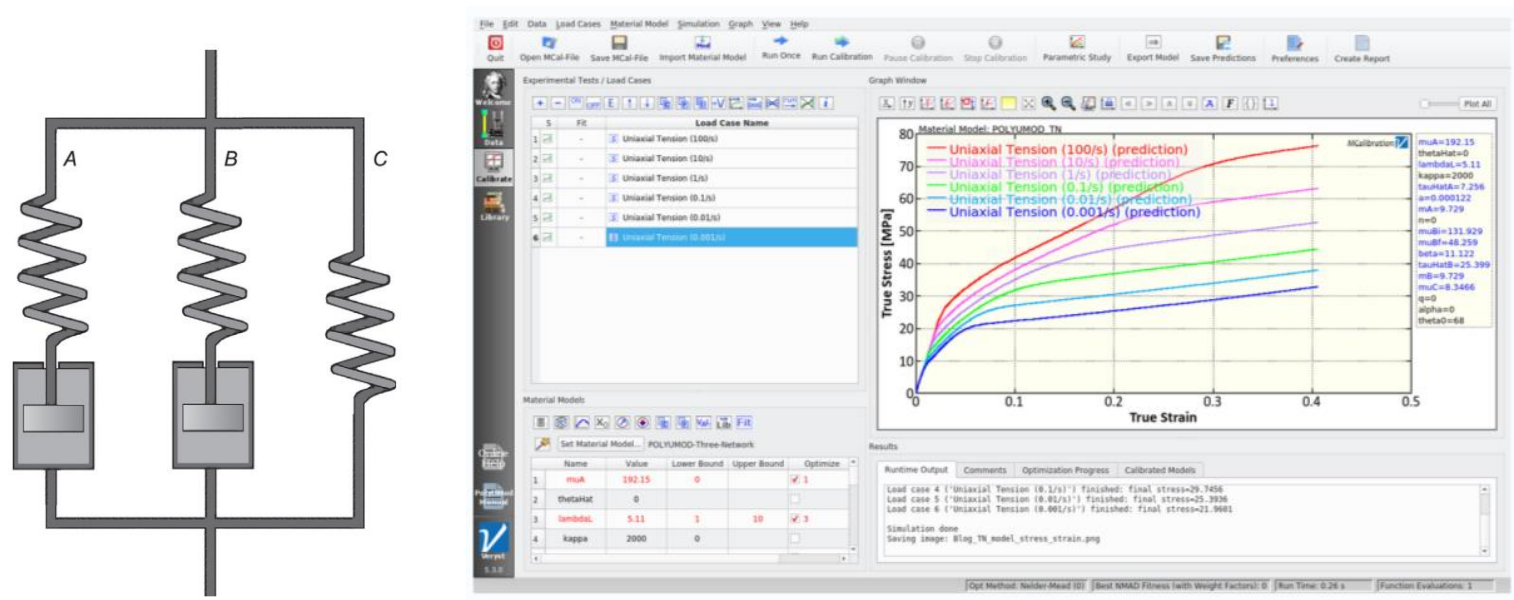

Figure 14: left) rheological representation of the Three-Network-Model [22] and right) set of stress-strain predictions from the Three-Network-Model created by MCalibration ${ }^{\circledR}$ [23]

UHMW-PE at different strain rates $5 ; 50 ; 500 \mathrm{~mm} / \mathrm{min}$

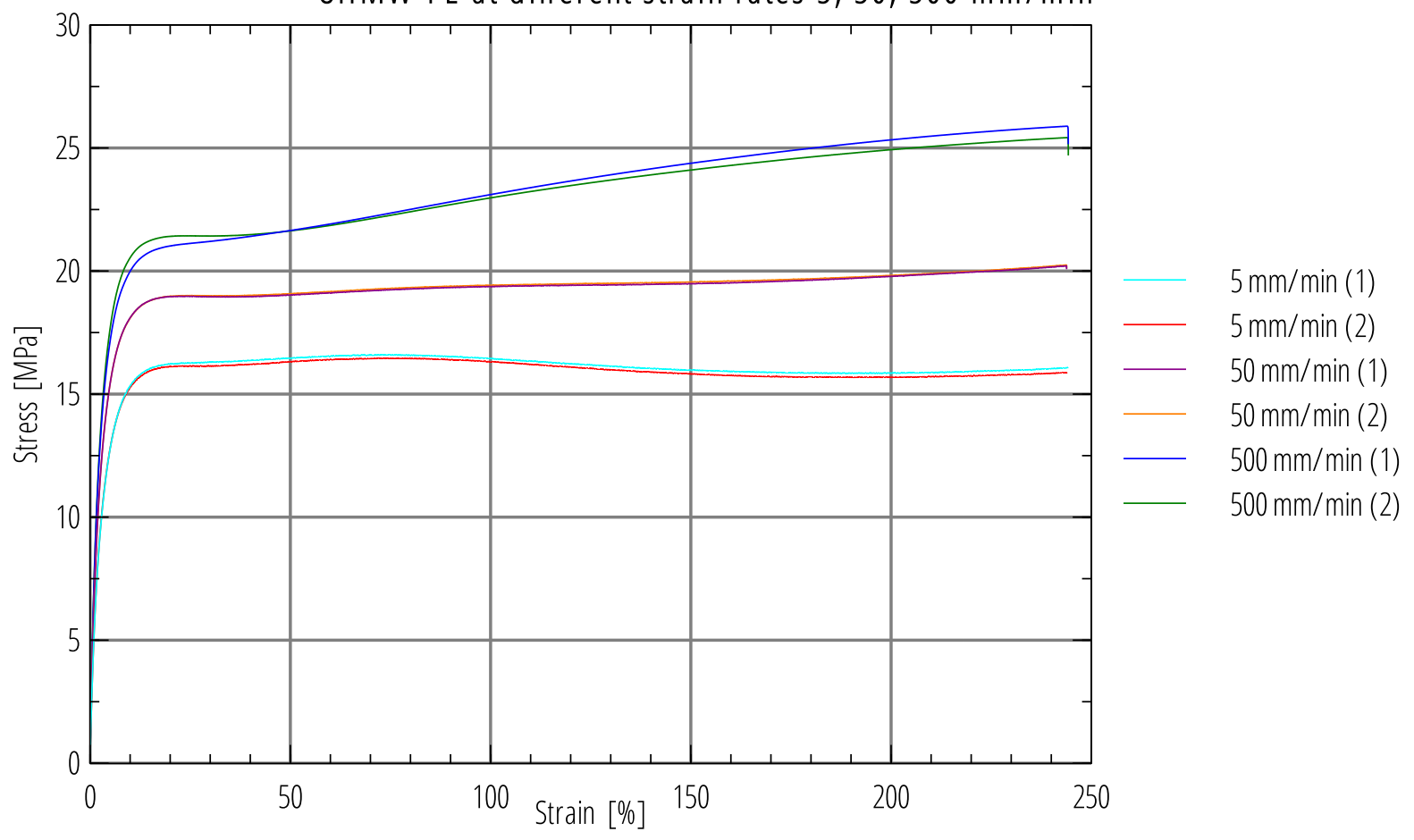

Figure 15: Tension test with 3 different strain rates of PE-UHMW 
The next step is to run 3D-simulations using the fitted material model and also the results of the indentation tests. Here, the halving of the model and the use of mass scaling are required to reduce computing time. The influence of mass scaling is briefly shown in Figure 16. The higher the scaling, the lower the computing time. The problem is, that this leads to strong oscillations of local pressure (as shown with model T3). Another possibility is shown in model $\mathrm{T} 10$ which uses variable mass scaling. In comparison to the other models, the mass scaling varies locally, dependent on the size of the mesh element. For smaller mesh elements, especially in the contact regions, the mass scaling is higher. This technique results in lowered oscillations and a halving of the computation time.
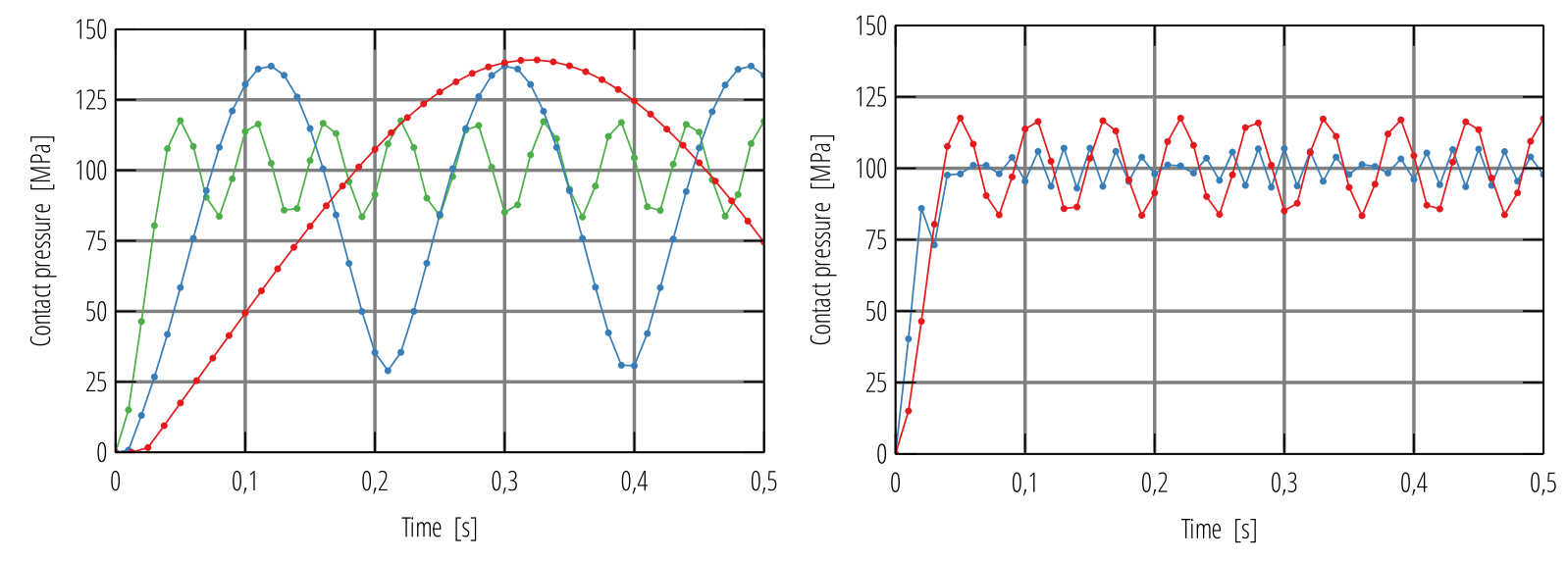

\begin{tabular}{|c|c|c|c|c|}
\hline model & mass scaling & computing time & stable increments & increments \\
\hline T03 & $1,0 \mathrm{e} 07$ & 00:12:02 & $1,205 \mathrm{e}-05 \mathrm{~s}$ & 41461 \\
\hline T04 & $1,0 \mathrm{e} 06$ & $00: 37: 36$ & $3,812 \mathrm{e}-06 \mathrm{~s}$ & 131092 \\
\hline T05 & $1,0 \mathrm{e} 05$ & 01:59:50 & $1,206 \mathrm{e}-06 \mathrm{~s}$ & 416886 \\
\hline $\mathrm{T} 10$ & variable & 01:08:18 & $2,144 \mathrm{e}-06 \mathrm{~s}$ & 233029 \\
\hline
\end{tabular}

Figure 16: Influence of mass scaling regarding computing time; ball indentation model with linear elastic and J2-plastic material behaviour; only differing in mass scaling setup

\section{Conclusion and Outlook}

This study intends to give an overview of the procedure for calculation the contact area with analytical and FEM solutions. The approaches for the analytical calculation and FEmodelling for single contact are set up. The analytical solution is based on Hertzian equations which are extended to viscose material properties, wherefrom the area of contact can be calculated. Due to the complex material model for polymers which is required for the FE-model, as a first step a 2D-model is used to calibrate the material model. Afterwards it can be integrated into a 3D-model. All necessary experiments for material characterization are defined, including tensile, indentation and friction tests. First results are presented.

Once the aim of calculating the contact area and pressure distribution of single contact in friction is reached, the results can be transferred to multiple contacts. For this purpose, a moulding tool which enables the configuration of different microstructures (on POM and $\mathrm{PP})$ is available. 


\section{Acknowledgement}

The research project was funded by the Federal Ministry of Economic Affairs and Energy (BMWi) through the "Otto von Guericke" German Federation of Industrial Research Associations (AiF) on the basis of a resolution of the German Bundestag as part of the programme to promote joint industrial research (IGF No. 20967 BG).

\section{References}

[1] Bergmann, A., Sumpf, J., Bartsch, R.: Tribologische Untersuchung und Beurteilung fördertechnisch relevanter polymerer Werkstoffe, Fachtagung über Verarbeitung und Anwendung von Polymeren (Technomer), Volume: 23 (2013)

[2] Bergmann, A.: Einfluss von verschiedenen Erodierstrukturen auf den Reibwert von Kunststoff-Kunststoff Paarungen, (2016). https://doi.org/10.13140/RG.2.2.13754.08648

[3] Richtlinie VDI 3400: Elektroerosive Bearbeitung; Begriffe, Verfahren, Anwendung; Düsseldorf, (1975)

[4] Baum, J.M.: Dry friction of microstructured polymer surfaced inspired by snake skin. Beilstein J. Nanotechnol., 5,: S. 1091-1103 (2014)

[5] Korpela, T.: Friction and wear of periodically micro-patterned polypropylene in dry sliding. Wear 289 S. 1-8 (2012)

[6] Korpela, T.: Wear and friction behaviour of POM surfaces with micro-structure controlled surface pressure. Wear 328 - 329 S. 262-269 (2015)

[7] He, B., et al.: Surface Texture Effect on Friction of a Microtextured Poly(dimethylsiloxane) (PDMS). Tribology Letters 31:187-197 (2008)

[8] Yu, C., Wang, Q.C.: Friction anisotropy with respect to topographic orientation, Sci. Rep. 2 (2012)

[9] Yu, C., et al.: Understanding Topographic Dependence of Friction with Micro- and Nano-Grooved Surfaces. Tribology Letters 53:145-156 (2014)

[10] Tomas, T et al., Analyse von Tangentialkräften in Längs - und Querrichtung bei der Kratzprüfung von glatten und genarbten ABS-Platten. Posterbeitrag des 14. Darmstädter Kunststofftags, Darmstadt (2016)

[11] Chivatanasoontorn, V., et al.: Surface texture effect on scratch behavior of injection molded plastics, Polym. Eng. Sci. 52:1862-1867 (2012)

[12] Jiang, H., et al.: Influence of surface roughness and contact load on friction coefficient and scratch behavior of thermoplastic olefins, Applied Surface Science 254:4494-4499 (2008)

[13] Seeger, P. et al., Addition of thermo-plastic polyurethane (TPU) to poly(methylmethacrylate) (PMMA) to improve its impact strength and to change its scratch behavior. Wear 406-407 (2018)

[14] Sumpf, J.; Schumann, A; Weise, S.; Nendel, K.; Eichhorn, S.: Neues Prüfverfahren zur Reibungs- und Verschleißbewertung von KunststoffGleitpaarungen. Tribologie und Schmierungstechnik 58, Heft 4, S. 47-50 (2011)

[15] Kunz, J.: Kontaktprobleme und ihre praktische Loesung, Konstruktion 11/12 2009, VDI Verlag (2009)

[16] Lafaye, S., et al.: The ploughing friction Analytical model with elastic recovery for a conical tip with a blunted spherical extremity, Tribology Letters, Vol. 21, No. 2:95-99 (2006)

[17] Lafaye, S., et al.: Analyzing friction and scratch tests without in situ observation, Wear 265: 664-673 (2008)

[18] Goddard, J., et al.: A Theory of Friction and Wear during the Abrasion of Metals, Wear 5:114-135 (1962)

[19] Rodriguez, P.: Contact and Friction in Systems with Fibre Reinforced Elastomers; Dissertation (2012)

[20] Dutschk, V.: Oberflächenkräfte und ihr Beitrag zu Adhäsion und Haftung in glasfaserverstärkten Thermoplasten. Dissertation, Dresden (2000) 
[21] Prokopovich, P., et al.: Comparison of JKR- and DMT-based multi-asperity adhesion model - theory and experiment. Colloids and Surfaces A: Physicochem. Eng. Aspects 383: 95-101 (2011)

[22] Bergström, J.: Mechanics of Solid Polymers: Theory and Computational Modeling, Elsevier (2015)

[23] https://polymerfem.com/three-network-model/; visited 07.10.2020 